\title{
OVIPOSIÇÃO DE ASCIA MONUSTE ORSEIS (GODART) (LEPIDOPTERA, PIERIDAE) EM COUVE COMUM
}

\author{
Cristina Schetino Bastos ${ }^{1}$ \\ Marcelo Picanço ${ }^{1}$ \\ Ailton Pinheiro Lôbo ${ }^{1}$ \\ Edimar Antônio da Silva ${ }^{1}$ \\ Ludmila Lafetá de Melo Neves ${ }^{1}$
}

\begin{abstract}
Oviposition OF ASCIA MONUSTE ORSEIS (GoDART) (LePIDOPTERA, PIERIDAE) IN KALE. This research was developed in green house of the Universidade Federal de Viçosa, in Viçosa, Minas Gerais State, Brazil and the objective was to evaluate oviposition patterns of Ascia monuste orseis (Godart, 1819) (Lepidoptera, Pieridae) in the canopy of Brassica oleracea Linnaeus plants. Ascia monuste orseis eggs were laid preferable during the morning period, in higher numbers in the stem of these plants and in the leaves of the lower part of the plants. Higher number of eggs was found in the lower parts of leaves of plants with no previous oviposition.

KEY WORDS. Lepidoptera, Pieridae, oviposition
\end{abstract}

Entre as brássicas de importância econômica, a couve (Brassica oleracea $\mathrm{L}$. var. acephala DC.), destaca-se pela riqueza em sais minerais, vitaminas e pela facilidade de cultivo (CARVALHO 1983; FANCELLI \& VENDRAMIM 1993). O curuquerê da couve, Ascia monuste orseis (Godart, 1819) constitui-se uma das pragaschave desta cultura no Brasil, sobretudo em regiões e estações de temperaturas mais elevadas. Sua oviposição ocorre nas folhas em grandes massas de coloração amarelada. Após a eclosão as lagartas passam por cinco ínstares. A pupação ocorre na superfície do solo ou na própria planta e os adultos são de coloração branco amarelada com os bordos das asas marrom escuros (SALGADO 1983; GALLO et al. 1988; FANCELLI \& VENDRAMIM 1993).

A parte do dossel, a face foliar, o período do dia e a existência de ovos nas folhas podem influenciar grandemente a taxa de oviposição dos insetos-praga nas plantas (LARA 1991). As diferentes partes do dossel podem possuir substâncias que inibem ou aceleram a oviposição do inseto como foi observado para Scrobipalpuloides absoluta (Meyrick, 1917) (Lepidoptera, Gelechiidae) por LEITE et al. (1995).

A preferência do inseto por ovipositar em determinadas partes da planta e em locais que não apresentem oviposição prévia, podem constituir importante estratégia de proteção à prole a condições adversas, bem como, de redução da

1) Departamento de Biologia Animal, Universidade Federal de Viçosa. 36571-000, Viçosa, Minas Gerais, Brasil. 
competição intra-específica. Já o período de oviposição pode estar relacionado à sua biologia, no que concerne a boas condições para o desenvolvimento de atividades como alimentação e acasalamento. Esta pesquisa objetivou o estudo da intensidade de oviposição de $A$. monuste orseis em couve comum, em função da face foliar, parte do dossel das plantas, presença de ovos nas folhas e período do dia.
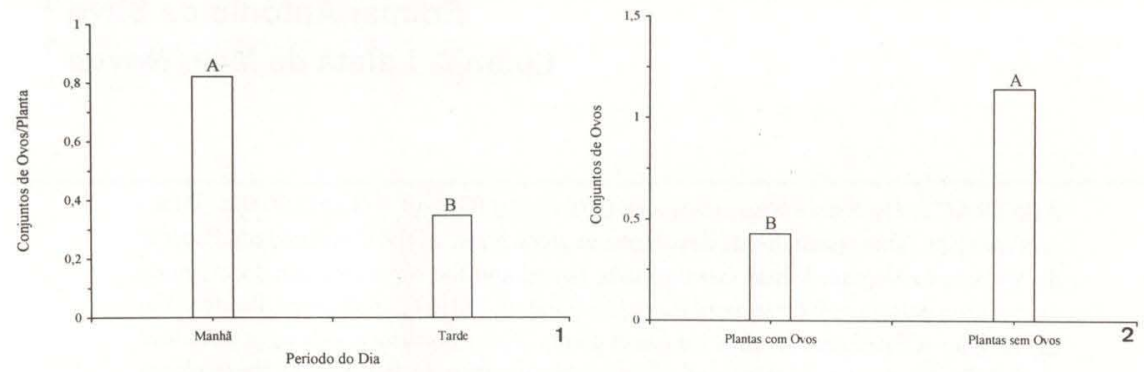

Figs 1-2. Intensidade de oviposição de Ascia monuste orseis em plantas de couve comum. (1) Em função do periodo do dia; (2) em função da presença de oviposição anterior desta espécie nas plantas. Histogramas seguidos pela mesma letra não diferem, entre si, pelo teste de Wilcoxon a $\mathrm{P}<0,05$.

\section{MATERIAL E MÉTODOS}

Esta pesquisa foi conduzida na casa-de-vegetação do Setor de Entomologia do Departamento de Biologia Animal, no Campus da Universidade Federal de Viçosa, Viçosa, Minas Gerais, durante o mês de novembro de 1993. Os fatores em estudo foram: presença ou não de ovos de Ascia monuste orseis nas plantas, o horário de oviposição do inseto (períodos da manhã ou da tarde), órgão da planta (caule ou folha), parte da folha (pecíolo ou limbo), face foliar (superior ou inferior) e posição das folhas no dossel das plantas (terços apical, mediano e basal).

O delineamento foi sem restrição na casualização com 40 tratamentos (Tab. I) e 14 repetições. A parcela foi representada por uma planta de couve comum de cerca de três meses de idade plantada em vaso de polietileno rígido de 5 litros. Ao final do período da manhã e da tarde, contaram-se o número de conjuntos de ovos presentes em cada face foliar, e a posição da folha nas plantas. Os dados experimentais foram submetidos aos testes não paramétricos de Wilcoxon e Kruskal-Wallis a $\mathrm{P}<0,05$.

\section{RESULTADOS E DISCUSSÃO}

A oviposição de Ascia monuste orseis ocorreu em maior intensidade no período da manhã do que no período da tarde (Fig. 1). BRUNINI \& SANTOS (1976) determinaram que a temperatura ótima de desenvolvimento desde o período de 
Tabela I. Relação dos tratamentos desta pesquisa.

\begin{tabular}{|c|c|c|c|c|c|c|}
\hline Tratamentos & $\begin{array}{l}\text { Presença } \\
\text { de ovos }\end{array}$ & Horário & $\begin{array}{l}\text { Orgão da } \\
\text { planta }\end{array}$ & $\begin{array}{c}\text { Posição do } \\
\text { dossel }\end{array}$ & $\begin{array}{l}\text { Parte do } \\
\text { órgão }\end{array}$ & $\begin{array}{c}\text { Face do } \\
\text { órgão }\end{array}$ \\
\hline 1 & Presente & Manhã & Caule & - & - & - \\
\hline 2 & Presente & Manhã & Folha & Apical & Pecíolo & - \\
\hline 3 & Presente & Manhã & Folha & Mediana & Pecíolo & - \\
\hline 4 & Presente & Manhã & Folha & Basal & Pecíolo & - \\
\hline 5 & Presente & Manhã & Folha & Apical & Limbo & Superior \\
\hline 6 & Presente & Manhã & Folha & Apical & Limbo & Inferior \\
\hline 7 & Presente & Manhã & Folha & Mediana & Limbo & Superior \\
\hline 8 & Presente & Manhã & Folha & Mediana & Limbo & Inferior \\
\hline 9 & Presente & Manhã & Folha & Basal & Limbo & Superior \\
\hline 10 & Presente & Manhã & Folha & Basal & Limbo & Inferior \\
\hline 11 & Presente & Tarde & Caule & - & - & - \\
\hline 12 & Presente & Tarde & Folha & Apical & Pecíolo & - \\
\hline 13 & Presente & Tarde & Folha & Mediana & Peciolo & - \\
\hline 14 & Presente & Tarde & Folha & Basal & Pecíolo & - \\
\hline 15 & Presente & Tarde & Folha & Apical & Limbo & Superior \\
\hline 16 & Presente & Tarde & Folha & Apical & Limbo & Inferior \\
\hline 17 & Presente & Tarde & Folha & Mediana & Limbo & Superior \\
\hline 18 & Presente & Tarde & Folha & Mediana & Limbo & Inferior \\
\hline 19 & Presente & Tarde & Folha & Basal & Limbo & Superior \\
\hline 20 & Presente & Tarde & Folha & Basal & Limbo & Inferior \\
\hline 21 & Ausente & Manhã & Caule & - & - & - \\
\hline 22 & Ausente & Manhã & Folha & Apical & Pecíolo & - \\
\hline 23 & Ausente & Manhã & Folha & Mediana & Pecíolo & - \\
\hline 24 & Ausente & Manhã & Folha & Basal & Pecíolo & - \\
\hline 25 & Ausente & Manhã & Folha & Apical & Limbo & Superior \\
\hline 26 & Ausente & Manhã & Folha & Apical & Limbo & Inferior \\
\hline 27 & Ausente & Manhã & Folha & Mediana & Limbo & Superior \\
\hline 28 & Ausente & Manhã & Folha & Mediana & Limbo & Inferior \\
\hline 29 & Ausente & Manhã & Folha & Basal & Limbo & Superior \\
\hline 30 & Ausente & Manhã & Folha & Basal & Limbo & Inferior \\
\hline 31 & Ausente & Tarde & Caule & - & - & - \\
\hline 32 & Ausente & Tarde & Folha & Apical & Pecíolo & - \\
\hline 33 & Ausente & Tarde & Folha & Mediana & Pecíolo & - \\
\hline 34 & Ausente & Tarde & Folha & Basal & Pecíolo & - \\
\hline 35 & Ausente & Tarde & Folha & Apical & Limbo & Superior \\
\hline 36 & Ausente & Tarde & Folha & Apical & Limbo & Inferior \\
\hline 37 & Ausente & Tarde & Folha & Mediana & Limbo & Superior \\
\hline 38 & Ausente & Tarde & Folha & Mediana & Limbo & Inferior \\
\hline 39 & Ausente & Tarde & Folha & Basal & Limbo & Superior \\
\hline 40 & Ausente & Tarde & Folha & Basal & Limbo & Inferior \\
\hline
\end{tabular}

incubação dos ovos até o final do ciclo evolutivo de $A$. monuste orseis é $25^{\circ} \mathrm{C}$, correspondendo ao desenvolvimento mais rápido e em maior número. Assim, isto justificaria a maior atividade no período da manhã, inclusive com respeito à preferência em ovipositar neste período, já que a temperatura se encontrava próxima ao ótimo requerido para desenvolvimento de suas atividades. O conhecimento desse comportamento torna-se fundamental no controle biológico desta praga por parasi- 
tóides de ovos os quais devem ser liberados no período em que ocorre a oviposição. Isso pode ser exemplificado pelo comportamento da fêmea do parasito de Anthonomus grandis (Boh., 1843) (Coleoptera, Curculionidae), Bracon vulgaris (Ashmead, 1889) (Hymenoptera, Braconidae) que mostrou maior atividade reprodutiva durante o período de luz do dia (PIEROzZI \& HABID 1993). Existem casos mais conhecidos em que isso já é feito como o uso de Trichograma galloi (Zucchi, 1988) (Hymenoptera, Trichogrammatidae), através de liberação na lavoura, no controle de Diatraea saccharalis (Fabricius, 1794) (Lepidoptera, Pyralidae) (BoTELHO et al. 1995).

Verificou-se que $A$. monuste orseis preferiu ovipositar em plantas que não possuíam oviposição anterior (Fig. 2) o que difere do comportamento adotado por outras espécies, como por exemplo Anthonomus grandis, que as fêmeas possuem senso discriminatório sobre botões ovipositados somente em baixo nível de infestação (até 10\%) (SOARES \& YAMAMOTO 1993). Tal fato pode ser devido à utilização de marcadores químicos pelas fêmeas do curuquerê nas folhas em que oviposita, o que impediria uma oviposição excessiva numa folha, reduzindo assim, a competição intra-específica entre as lagartas eclodidas (MITCHELL 1975; GIGA \& SMITH 1981). SCHOONHOVEN et al. (1993) verificaram que glândulas acessórias de Pieris brassicae (Linnaeus, 1758) (Lepidoptera, Pieridae) produzem substância inibidora à oviposição de $P$. brassicae. O mesmo foi observado por BLAAKMEER et. al. (1994a) que encontraram associados aos ovos de $P$. brassicae marcadores químicos que funcionaram como deterrentes à oviposição deste inseto. Já BLAAKMEER et al. (1994b) encontraram que alcalóides miriamidas são compostos deterrentes produzidos pelas folhas de repolho em resposta à oviposição de $P$. brassicae.

Observou-se preferência de oviposição na folha em relação ao caule, e pelo limbo em relação ao pecíolo (Figs 3-4), sendo esta preferência por tecidos mais tenros, em detrimento aos tecidos lenhosos. Assim, quando as larvas eclodirem, as lagartas terão sua alimentação favorecida, já que recém-eclodidas ainda não possuem o potencial para alimentar-se de materiais mais lenhosos, capacidade esta, que será adquirida somente nos últimos ínstares (GALLO et al. 1988).

O dossel superior da planta foi preferida para oviposição, seguido da média e inferior (Fig. 3). Tal fato pode ser explicado, possivelmente, pelo maior teor de aminoácidos livres e menor teor de substâncias tóxicas ao inseto nas folhas mais jovens (EPSTEIN 1975; MARSCHNER 1995). Pois este mesmo aspecto tem sido relacionado em diversas culturas com o favorecimento do desempenho de larvas recém-eclodidas de diversas espécies de insetos (SOGAWA 1982; MARSCHNER 1995). Isso também foi comprovado para outras espécies de insetos, quando larvas são alimentadas com dietas. CANATO \& ZUCOLOTO (1993), ao alimentarem larvas de Ceratitis capitata (Wiedemann, 1824) (Diptera, Tephritidae) com dietas a base de levedo, observaram que a medida que se aumentava a quantidade de levedo na dieta, dentro de limites, a porcentagem de emergência era aumentada. Isso por ser o levedo de cerveja um alimento muito rico em proteínas, aminoácidos livres, sais minerais e vitaminas do complexo B (VANDERZANT 1974).

A oviposição de $A$. monuste orseis foi cerca de duas vezes mais intensa na face inferior do que na superior (Fig. 2). NOMURA \& YAMASHITA (1975), encon- 
traram que na couve os ovos são depositados na face inferior das folhas, podendo-se notá-los também na face superior. Já na beterraba e no agrião, também utilizadas como fonte alimentar e que apresentam folhas menores que as da couve, só foram encontrados na face superior. Segundo GALLo et al. (1988) geralmente a postura de $A$. monuste orseis é feita na face inferior das folhas, em grupos não muito juntos. A preferência por ovipositar na face inferior pode representar uma tática de proteção dos ovos à ação das intempéries (sol e chuva) e inimigos naturais.
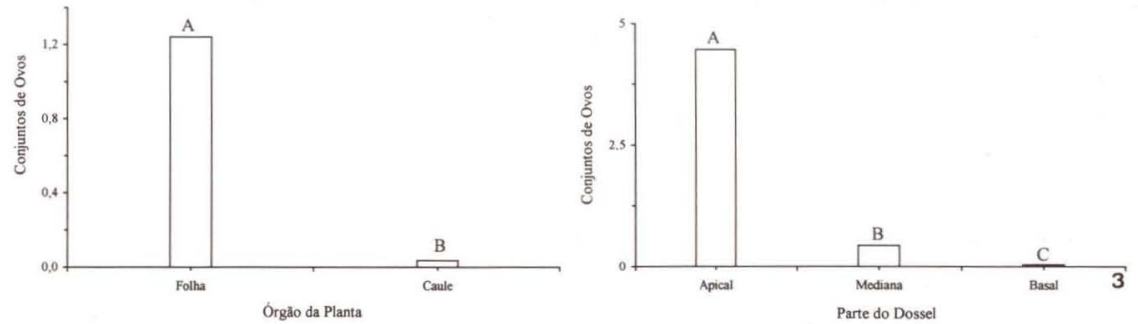

Fig. 3. Intensidade de oviposição de Ascia monuste orseis nos órgãos e nas partes do dossel das plantas de couve comum. Histogramas seguidos pela mesma letra não diferem, entre si, pelo teste de Kruskal-Wallis a $\mathrm{P}<0,05$.
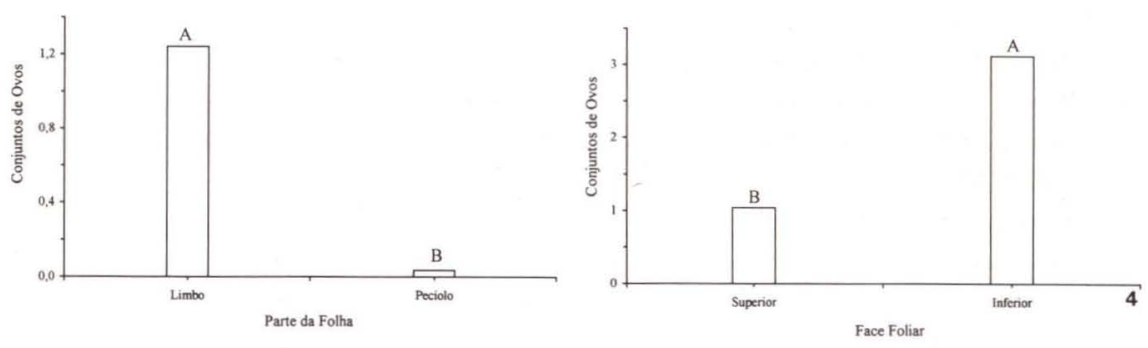

Fig. 4. Intensidade de oviposição de Ascia monuste orseis nas partes e faces das folhas de couve comum. Histogramas seguidos pela mesma letra não diferem, entre si, pelo teste de Wilcoxon a $\mathrm{P}<0,05$. 


\section{REFERÊNCIAS BIBLIOGRÁFICAS}

BlaAkMEer, A.; A. STORK; A. VAN VeldhUIZEN; T.A. VAn BeEK; A. DE GRoOT; J.J.A. VAN LOON \& L.M. SCHOONHOVEN. 1994a. Isolation, identification, and synthesis of miriamides, new hostmarkers from eggs of Pieris brassicae. Jour. Nat. Prod. 57 (1): 90-99.

BlaAkmeer, A.; D. van Der Wal; A. Stork; T.A. van BeeK; A. DE Groot \& J.J.A. VAN LOON. 1994b. Plant response to eggs vs. host marking pheromone as factors inhibiting oviposition by Pieris brassicae. J. Chem. Ecol. 20 (7): 1657-1665.

Botelho, P.S.M.; J.R.P. ParRa; E.A. Magrini; M.L. Haddad \& L.C.L. RESENDE. 1995. Parasitismo de ovos de Diatraea saccharalis (Fabr.) por Trichogramma galloi Zucchi, em diferentes variedades de cana-de-açúcar. An. Soc. Entomol. Brasil 24 (1): 141-145.

BRUNINI, O. \& J.M. DOs SANTOS. 1976. Comportamento de Ascia monuste orseis em função da temperatura do ar. Ciên. Cult. 28 (6): 681-683.

CANATO, C.M. \& F.S. ZUCOLOTO. 1993. Influência da concentração de nutrientes no valor nutritivo e seleção de dietas em larvas de Ceratitis capitata Wied. (Diptera: Tephritidae). An. Soc. Entomol. Brasil 22 (3): 471-476.

Carvalho, V.D. DE. 1983. Propriedades químicas das brássicas. Inf. Agrop. 9 (98): 54-56.

EPSTEIN, E. 1975. Nutrição mineral de plantas: princípios e perspectivas. São Paulo, EDUSP, 341p.

FANCELLI, M. \& J.D. VENDRAMIM. 1993. Não preferência para alimentação e oviposição de Ascia monuste orseis (Godart) (Lepidoptera: Pieridae) em cultivares de couve. An. Soc. Entomol. Brasil 22 (2): 231-236.

Gallo, D.; O. NaKano; S. Silveira Neto; R.P.L. Carvalho; G.C. DE Batista; E. BERTI FILHO; J.R.P. PARRA; R.A. ZUCCHI; S.B. AlVES \& J.D. VENDRAMIM. 1988. Manual de Entomologia agrícola. São Paulo, Agronômica Ceres, 649p.

GiGA, D.P. \& R.H SMITH. 1981. Varietal resistance and intraspecific competition in the cowpea weevils Callosobruchus maculatus and C. chinensis. Jour. Appl. Ecol. 18 (3): 755-761.

LARA, F.M. 1991. Princípios de resistência de plantas a insetos. São Paulo, Editora Ícone, 336p.

LeITE, G.L.D.; M. PICANÇO; D.J.H. DA Silva; A.C. DA MATA \& G.N. JHAM. 1995. Distribuição de oviposição de Scrobipalpuloides absoluta no dossel de Lycopersicon esculentum, L. hirsutum e L. peruvianum. Hortic. bras., Brasília, 13 (1): 47-51.

MARSCHNER, H. 1995. Mineral nutrition of higher plants. San Diego, Academic Press, $879 \mathrm{p}$.

MitcheLL, R. 1975. The evolution of oviposition tacties in the bean weevil, Callosobruchus maculatus. Ecology 56 (3): 696-702.

NOMURA, H. \& I. YAMASHITA. 1975. Desenvolvimento do curuquerê-da-couve, Ascia monuste orseis (Linnaeus, 1764) (Lepidoptera, Pieridae), em laboratório. Rev. Brasil. Biol. 35 (4): 799-803. 
PIEROZZI JR., I. \& M.E.M. HABIB. 1993. Aspectos biológicos e de comportamento dos principais parasitos de Anthonomus grandis Boh. (Coleoptera: Curculionidae), em Campinas, SP. An. Soc. Entomol. Brasil 22 (2): 317-323. SALGADO, L.O. 1983. Pragas das brássicas, características e métodos de controle. Inf. Agrop., Belo Horizonte, 9 (98): 43-47.

SCHOONHOVEN, L.M. 1993. Two related butterfly species avoid oviposition near each other's eggs. Experentia 46 (5): 526-528.

SoARes, J.J. \& P.T. YAmamoto. 1993. Comportamento de oviposição de Anthonomus grandis Boh. (Coleoptera: Curculionidae) em diferentes níveis de infestação natural. An. Soc. Entomol. Brasil 22 (2): 333-339.

SogAWA, K. 1982. The rice brow plant hopper: feeding phisiology and host plant interactions. Ann. Rev. Entomol. 27: 49-73.

VANDERZANT, E.S. 1974. Development significance and application of artificial diets for insects. Ann. Rev. Entomol. 19: 139-160.

Recebido em 17.VI.1996; aceito em 05.V.1997. 